\title{
Explanation of land use in mountainous area, China: from field to village level
}

\author{
Jing'an Shao - Chiying Xu • Chaofu Wei • \\ Deti Xie
}

Published online: 22 November 2007

(C) Springer Science+Business Media B.V. 2007

\section{Erratum to: GeoJournal 68(4): 357-368 (2007) DOI 10.1007/s10708-007-9089-5}

After publication of this article, it has been discovered that Shao et al. have infringed copyright of the article by: Overmars, K.P., Verburg, P.H., 2006. Multilevel modelling of land use from field to village level in the Philippines. Agricultural Systems 89 (2-3): 435-456

We sincerely apologize for this plagiarism.

The online version of the original article can be found under doi:10.1007/s10708-007-9089-5.

J. Shao $(\bowtie) \cdot$ C. Wei · D. Xie

College of Resource and Environment, Southwest

University, Chongqing 400716, China

e-mail: shaoja@1reis.ac.cn

J. Shao

Institute of Geographic Sciences and Natural Resources

Research, CAS, Beijing 100101, China

C. $\mathrm{Xu}$

College of Foreign Language, Southwest University,

Chongqing 400715, China 